\title{
Desain Interior Ex-Wisma Barbara sebagai Sentra UKM kawasan Jarak-Dolly
}

\author{
Tegar Aditya Cahyadi, Mahendra Wardhana \\ Departemen Desain Interior, Fakultas Teknik Sipil dan Perencanaan, Institut Teknologi Sepuluh \\ Nopember (ITS) \\ Jl. Arief Rahman Hakim, Surabaya 60111 \\ E-mail: mahendrawardhana@interior.its.ac.id
}

\begin{abstract}
Abstrak - Dua tahun setelah penutupan kawasan lokalisasi Jarak-Dolly, perekonomian Jarak-Dolly perlahan bangkit dengan berdirinya UKM-UKM dan perencanaan dolly sebagai kawasan edu-wisata oleh LSM dan Pemerintah Kota Surabaya. Untuk mengoptimalkan pengembangan UKM, dibutuhkan fasilitas pendukung untuk memasarkan produk. Dalam penelitian ini, penulis mengambil data eksisting UKM binaan Gerakan Melukis Harapan, serta melakukan pengamatan dan pengambilan data langsung di kawasan Jarak-Dolly. Penulis menggunakan bangunan ex-Wisma Barbara sebagai objek desain, untuk kemudian dialih fungsikan menjadi Sentra UKM yang akan mendukung aktifitas pengembangan UKM, memperkenalkan produk-produk UKM, memperkenalkan sejarah dari kawasan jarak dolly serta aktifitas edu-wisata kawasan Jarak-Dolly dengan nilai historis, pembinaan, dan edukatif.
\end{abstract}

Kata Kunci- Jarak-Dolly, Sentra UKM, Historis, pembinaan, edukatif.

\section{PENDAHULUAN}

$\mathrm{D}$ ALAM sejarahnya, kawasan Dolly dahulu adalah tempat pemakaman warga Tionghoa, meliputi wilayah Girilaya, berbatasan dengan makam Islam di Putat Gede. Menurut Purnomo dan Siregar (1982), Gang Dolly barawal pada tahun 1967, saat Dolly Khavit, seorang perempuan yang konon bekas pekerja seks komersil (PSK) membuka usaha pelacuran dan membangun wisma bernama Barbara. Setelah itu, muncul wisma lain dan akhirnya di awal tahun 1970-an perkampungan itu berubah nama menjadi Gang Dolly. Semakin lama Gang Dolly semakin dikenal masyarakat. Kondisi tersebut kemudian berpengaruh pada kuantitas pengunjung dan jumlah PSK. Gang Dolly juga menjelma menjadi kekuatan dan sandaran hidup bagi penduduk di sana. Ada lebih dari 800 wisma esekesek, kafe dangdut, dan panti pijat plus. Setidaknya setiap malam sekitar 9.000 lebih PSK, pelacur di bawah umur, germo, dan ahli pijat hingga Gang Dolly kemudian mendapat predikat sebagai lokalisasi terbesar se-Asia Tenggara mengalahkan Patpong di Bangkok, Thailand dan Geylang di Singapura (Purnomo dan Sirager, 1982).

Kehidupan masyarakat di wilayah lokalisasi mendapat pengaruh langsung dari keberadaan lokalisasi tersebut. Dolly menjadi tumpuan hidup masyarakat sekitar, mulai dari pedagang makanan yang berkeliling menjajakan makanannya, pedagang makanan dan minuman yang menetap, penjual pakaian wanita, tukang parkir, penjual minuman dan makanan di bar, salon kecantikan, tempat-tempat spa beserta panti pijatnya, waiterss yang mengantarkan minuman kepada pelanggan, bisnis laundry pakaian, toko-toko kelontong, dll. Dengan kehidupan yang telah dijalaninya sekian tahun lamanya di sekitar Lokalisasi Jarak Dolly, maka orang-orang yang secara tidak langsung berhubungan dengan wismawisma disana sebetulnya sangat menggantungkan kehidupannya atas eksistensi Lokalisasi Jarak Dolly itu sendiri, penghasilan yang mereka dapatkan juga bergantung terhadap keberadaan lokalisasi. Maka dari itu, tidak mudah untuk melakukan penutupan dan penggusuran Lokalisasi Jarak Dolly. Setelah melalui proses panjang, Mulai dari memberikan program bagi para PSK agar tidak lagi beroperasi dengan membekali kemampuan usaha dan modal, melakukan pemulangan kekampung halaman, membeli seluruh wisma yang ada dengan total 311 wisma, dan program lainnya, yang bersamaan dengan adanya penolakan dari Mucikari dan PSK di Gang Dolly, Pemerintah Kota Surabaya akhirnya berhasil mendeklarasikan penutupan kawasan Jarak-Dolly pada tanggal 19 Juni 2014 (Info Singkat kesejahteraan sosial, DPR RI Vol. VI, No.13/I/P3DI/Juli/2014).

Tiga tahun setelah adanya penutupan kawasan lokalisasi Jarak-Dolly perekonomian dan kondisi sosial kawasan Dolly perlahan-lahan pulih, hal ini didukung oleh kegiatan-kegiatan pengembangan masyarakat yang diberikan oleh Pemerintah Kota Surabaya serta organisasi-organisasi sosial dan pemuda yang memiliki kepedulian untuk membangun kembali kawasan Jarak Dolly serta adanya rencana jangka panjang mengenai pengembangan Gang dolly dan kawasan JarakDolly mejadi kawasan wisata edukatif baru kota Surabaya. Melalui dinas terkait, LSM, dam Organisasi kepemudaan lainnya, saat ini telah terbentuk beberapa unit Usaha Kecil Menengah (UKM) di kawasan Jarak-Dolly yang dikelola langsung oleh masyarakat Jarak-Dolly.

Dalam mengoptimalkan pengembangan UKM yang ada dan membentuk UKM baru dibutuhkan fasilitas pendukung untuk memasarkan produk serta memperkenalkan aktifitas masyarakat kepada para wisatawan yang datang ke kampung wisata edukatif Jarak-Dolly. Dengan eksisting Ex-Wisma barbara, bangunan 6 lantai yang dulunya merupakan bangunan lokalisasi terbesar di Gang Dolly yang saat ini sudah dibeli oleh Pemerintah Kota Surabaya. Penulis mendesain sebuah Sentra UKM yang nantinya akan memfasilitasi pengembangan UKM dan menjadi tempat untuk memasarkan produk UKM kapada calon konsumen. Bagi para pengunjung Sentra UKM ini tidak hanya menjadi tempat untuk membeli 
produk UKM, desain interior Sentra UKM ini akan memberikan pengalaman berbeda dengan nilai edukatif dan historis, yang akan diterapkan melalui konten-konten yang informatif serta transformasi karakter dan kebudayaan setempat. Sentra UKM juga akan memiliki nilai pembinaan melalui program-program bagi pengunjung dan para pelaku UKM serta sinergi sentra UKM dengan kampung-kampung wisata didalam kawasan Jarak-Dolly. Nilai-nilai dan konsep desain yang akan diterapkan nantinya akan menjadi daya dukung pengembangan wisata Jarak-Dolly dengan sasaran para wisatawan dan pengembangan sentra UKM yang berbeda dari Sentra UKM yang ada di kota Surabaya saat ini.

\section{A. Rumusan Masalah}

1) Identifikasi Masalah

1. Belum adanya fasilitas pendukung untuk memasarkan dan mempromosikan produk UKM kawasan JarakDolly.

2. Belum adanya fasilitas untuk kegiatan pengembangan UKM kawasan Jarak-Dolly.

3. Belum adanya fasilitas pendukung untuk memperkenalkan aktifitas masyarakat kepada para wisatawan kampung edukatif Jarak-Dolly

4. Belum adanya konsep desain interior yang memfasilitasi kegiatan-kegiatan UKM dan pengembangan wisata edukatif Jarak-Dolly dalam pengembangan Ex-Wisma Barbara sebagai Sentra UKM.

\section{2) Rumusan Masalah}

Ex-Wisma Barbara yang akan dikembangkan sebagai fasilitas untuk memasarkan dan mempromosikan produk UKM memiliki peranan penting bagi pengembangan UKM kawasan Jarak-Dolly, tidak hanya berperan bagi kegiatan UKM, Fasilitas yang terdapat di Desain Interior Ex-Wisma Barbara nantinya juga menjadi daya dukung dalam pengembangan kawasan Jarak-Dolly menjadi kawasan wisata baru dan edukatif di kota Surabaya. Berdasarkan hal tersebut, perumusan masalah yang dapat diuraikan adalah sebagai berikut:

1. Konsep desain interior Ex-Wisma Barbara yang mampu memfasilitasi kegiatan-kegiatan pengembangan UKM kawasan Jarak-Dolly.

2. Desain interior yang mendukung pengembangan wisata edukatif kawasan Jarak-Dolly.

\section{3) Batasan Masalah}

1. Luas keseluruhan bangunan minimal $800 \mathrm{~m}^{2}$.

2. Desain tidak merubah konstruksi bangunan.

3. Tata letak ruangan menyesuaikan bentuk arsitektur bangunan eksisting.

4. Perubahan dinding, pintu, dan jendela dimungkinkan tanpa merubah bentukan bangunan secara masif.

\section{B. Tujuan}

Me-redesain interior Ex-Wisma Barbara sebagai pusat pengembangan masyarakat, yang mampu memfasilitasi kegiatan-kegiatan pengembangan UKM dan medukung pengembangan serta perencanaan kawasan Jarak Dolly sebagai kawasan wisata baru dan edukatif di Kota Surabaya. c. Manfaat

1) Bagi Usaha kecil Menengah (UKM) kawasan JarakDolly.

- Memberikan sebuah sarana dan prasarana yang mampu memfasilitasi kegiatan pengembangan UKM mulai dari kegiatan pemasaran hingga kegiatan promosi produk UKM ke Masyarakat.

- Memberikan sebuah fasilitas yang bisa menjadi sumber pemasukan dan penghasilan baru masyarakat Jarak Dolly.

- Wadah untuk membangun citra positif masyarakat kawasan Jarak Dolly baik secara individu dan kelompok dalam mendukung wajah baru kawasan Jarak Dolly sebagai kawasan wisata edukatif.

2) Bagi Pemerintah Kotra Surabaya

- Sebagai sarana untuk melihat perkembangan dunia pendidikan tinggi dimana para lulusannya dapat menjadi aset sumber daya manusia yang potensial bagi dunia kerja.

- Memperoleh berbagai masukan berupa ide-ide pengembangan desain dari mahasiswa praktikan dalam ranka perencanaan wilayah kota kedepannya khususnya pengembangan kawasan Jarak Dolly.

3) Bagi Penulis

- Dapat menambah pengalaman serta pengetahuan tentang penerapan keilmuan Desain Interior.

- Berkontribusi dalam mengaplikasikan keilmuan dalam membantu menyelesaikan permasalahan dilingkungan sekitar.

- Mengetahui kondisi berbagai lapisan masyarakat sabagai bentuk pembelajaran diri dan pengaplikasian Tri Dharma Perguruan Tinggi.

\section{URAIAN PENELITIAN}

\section{1) Tahap Identifikasi Obyek}

Tahap ini adalah tahap untuk menentukan latar belakang, judul, dan definisi judul. Pada tahap ini akan diuraikan dasardasar pemikiran dan landasan yang menjadi alasan untuk melakukan studi tentang desain interior Gedung Ex-Wisma Barbara.

2) Tahap Identifikasi Masalah

Tahapan ini dilakukan untuk tujuan dan manfaat serta permasalahan yang ditemukan untuk mencapai tujuan guna mendapatkan manfaat dari perencanaan dan desain interior Ex-Wisma barbara. Tujuan analisa merupakan hal-hal yang ingin dicapai sebagai hasil akhir dari proses-proses yang dilakukan.

3) Tahap dan Metode Pengumpulan Data

Dalam melakukan perancangan, data yang dikumpulkan dibagi menjadi dua jenis, yaitu data primer dan data sekunder. Data primer merupakan data yang didapat secara langsung dengan pihak yang bersangkutan di lapangan. Sedangkan data sekunder merupakan data yang didapatkan dari pihak yang tidak bersangkutan secara langsung yaitu melalui studi literatur.

\section{4) Tahap Analisa Data}

Dalam perancangan ini metode analisis data yang digunakan adalah metode deskrisptif kualitatif. Perancangan dilakukan dengan melakukan analisa dan pengamatan terhadap kebutuhan pengguna. Mengetahui kebutuhan 
pengguna ruang melalui perilaku yang dilakukan dalam sebuah bangunan yang difungsikan menjadi sentra ukm dan perpustakaan, dilakukan berdasarkan prosedur pengamatan fenomena sosial. Sehingga, hasil perancangan yang didapatkan tidak bersifat statistik dan tidak ada aturan absolut dalam mengolah hasil pengamatan (data). Perancangan ini memfokuskan pada studi kasus yang merupakan analisa perancangan lebih rinci terhadap objek tertentu secara mendalam dan menyeluruh.

\section{5) Metode Desain}

Di dalam sebuah metode desain diharuskan mengetahui kata kunci utama untuk desain interior Ex-Wisma Barbara sebagai Sentra UKM kawasan Jarak-Dolly:

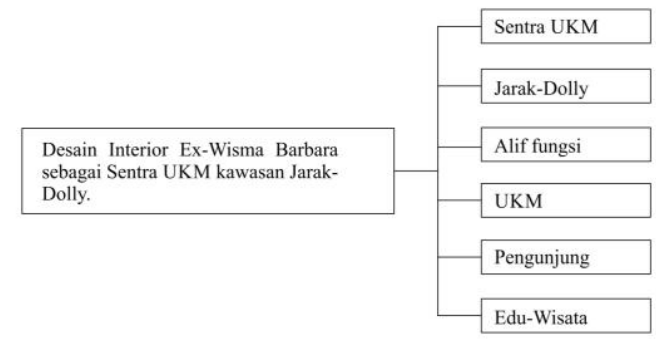

Gambar 1. Keyword penelitian

Untuk menghasilkan konsep desain yang baik dan mampu memberi solisi dan gagasan baru terhadap permasalahan yang diangkat, maka dibutuhkan sebuah alur metodologi desain, metodologi desain delam desain interior Ex-Wisma Barbara sebagai Sentra UKM kawasan Jarak-Dolly adalah:

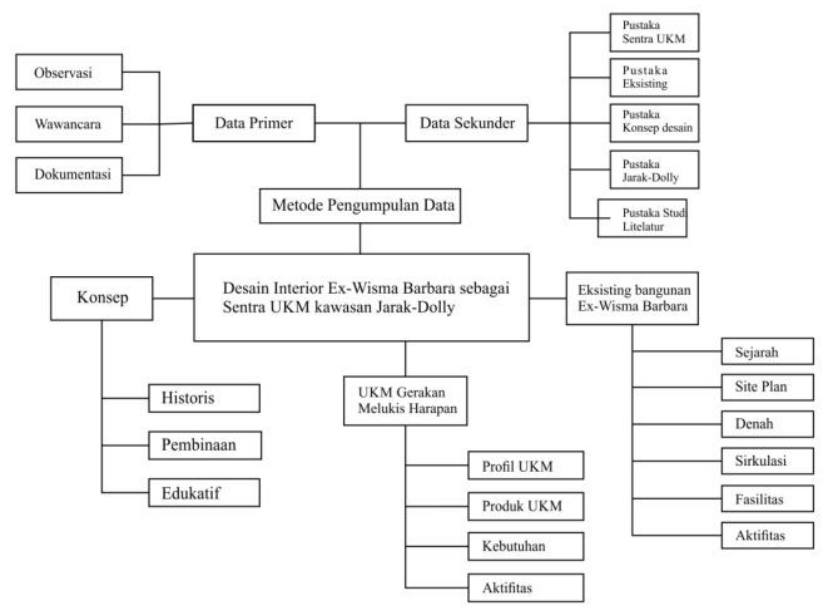

Gambar 2. Metode Desain

\section{KONSEP DESAIN}

\section{A. Konsep Makro}

Konsep makro yang diterapkan pada interior Ex-Wisma Barbara bersumber pada penyelesaian permasalahan yang terjadi pada objek desain dan gambaran pengembangan kawasan Jarak-Dolly kedepan. Dari analisa yang dilakukan terdapat tiga nilai yang diangkat pada penerapan desain kali ini, pertama adalah nilai Edukatif, kedua adalah pembinaan dan yang ketiga yaitu kepahlawanan. dari 3 nilai yang akan diangkat penulis kemudian merumuskan konsep dan tema desain yang akan diterapkan. Konsep yang akan diterapkan pada Sentra UKM Jarak-Dolly adalah konsep desain dengan nilai Kampung Pahlawan Jarak-Dolly. Konsep desain Kampung Pahlawan Jarak-Dolly akan dijabarkan melalui 3 nilai.

\section{1) Aplikasi nilai edukatif}

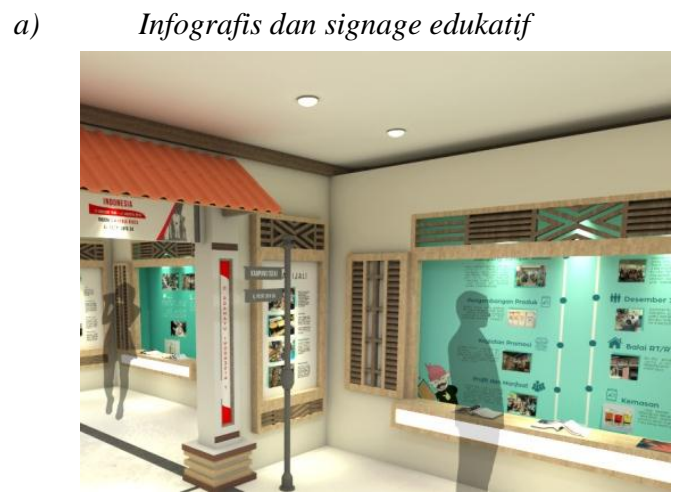

Gambar 3. View infografis ruang Sentra UKM dan Pusat Oleh-oleh

Infografis dan signage akan menyampaikan materi-materi edukatif dengan desain yang menarik tentang UKM, Gang Dolly, dan Kota Surabaya. selain itu infografis juga akan membawa pengunjung masuk kedalam suasana kawasan Jarak-dolly khususnya kampung-kampung eduwisata yang suasananya langsung dihadirkan di dalam sentra UKM.

\section{B. Elemen estetis transformatif}

Elemen estitis yang diaplikasikan tidak hanya elemen estetis yang menambah estatika saja, namun memiliki latar belakang transformasi budaya setempat. Pengaplikasiannya dengan penggunaan Elemen estetis berasal dari transformasi bentuk gapura dan transformas bentuk daun jarak serta motif batuk jarak arum.

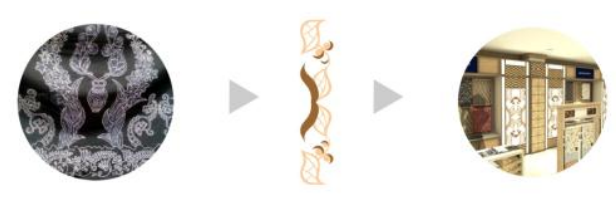

Gambar 4. Transformasi bentuk motif batik

Penulis menganalisa bentuk motif kain batik jarak arum, kemudian salah satu bentuk motif batik pada kain ditransformasikan menjadi bentuk yang lebih sederhana. Bentuk penyederhanaan tersebut kemudian diterapkan pada elemen estetis dan direalesasikan dengan material yang tepat.
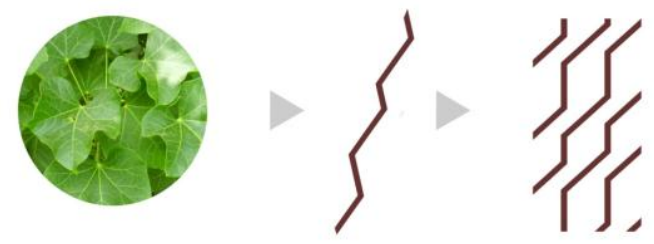

Gambar 5. Transformasi bentuk motif batik 
Sama seperti transformasi motif batik, Penulis menganalisa bentuk daun jarak yang merupakan tanaman yang menjadi cikal bakal nama kawasan Jarak-Dolly, bentuk daun jarak kemudian di sederhanakan.

Bentuk penyederhanaan tersebut kemudian diterapkan pada elemen estetis dan direalesasikan dengan material yang tepat. 2. Aplikasi nilai pembinaan

\section{Program dan Fasilitas Ruang}

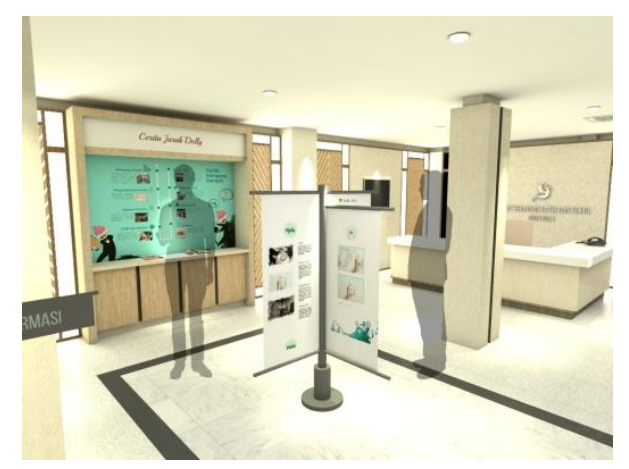

Gambar 6. View ruang Lobby utama

Tersedianya fasilitas ruang yang berperan dalam mengembangkan masyarakat Jarak-Dolly dan pengunjung, Didalam wisama barbara tidak hanya menjadi fasilitas yang memiliki pola hubungan 1 arah, namun akan ada program yang sifatnya 2 arah dan membangun komunikasi antara Sentra UKM dengan pengunjung, misalnya melalui program Workshop bagi anak-anak dan pengunjung, Nonton film dokumenter dan program lainnya. Kelengkapan fasilitas ini bertujuan untuk membuat pengunjung lebih betah lagi, hal ini sesuai dengan pendapat Wardhana (2015).

\section{Program daya dukung lingkungan}

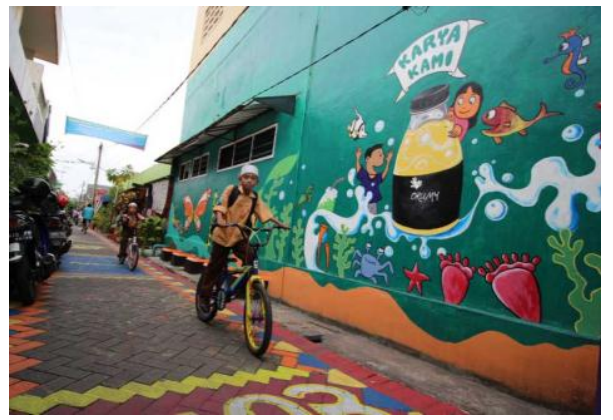

Gambar 7. Mural di Gang Dolly

Dampak adanya sentra UKM Ex-Wisma Barbara akan dirasakan oleh masyarakat di kawan Jarak-Dolly, wisma barbara akan membangun sebuah sistem eduwisata dimana pengunjung tidak hanya merasakan pengalaman di wisma barbara, tapi akan terhubung ke kampung-kampung eduwisata dikawasan Jarak-Dolly. Desain interior Sentra UKM akan mengenalkan lingkungan Jarak-Dolly saat ini khususnya pasca penutupan melalui elemen-elemen estetis yang diterapkan. 3. Aplikasi nilai Historis

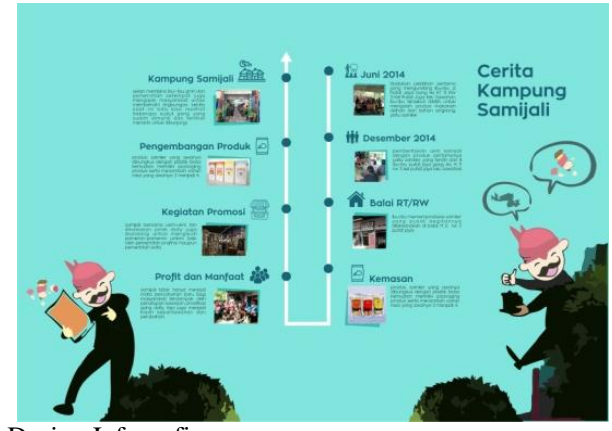

Gambar 8. Design Infografis

Desain interior Sentra UKM akan mengangkat kembali Sejarah dan cerita tentang Surabaya dan Gang Dolly melalui infografis yang menarik.

\section{E. Konsep Mikro}

1) Konsep Lantai

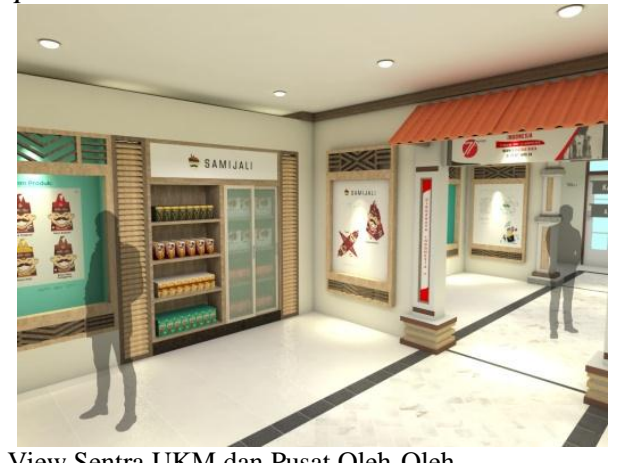

Gambar 9. View Sentra UKM dan Pusat Oleh-Oleh

Konsep lantai juga berperan sebagai zoning ruang, yang akan menjadi area sirkulasi bagi pengunjung. konsep lantai juga merupakan transformasi bentuk dari suasana gang kawasan Jarak-Dolly dengan pemilihan material yang bisa mengilustrasikan susunan paving-paving kampung-kampung wisata Jarak-Dolly. Perkuatan sirkulasi ini juga sesuai dengan pendapat Wardhana (2016).

\section{2) Konsep Dinding}

Pemilihan warna dinding menggunakan warna-warna netral dan hangat, dinding Sentra UKM juga menjadi elemen etetis transformasi bentuk dari suasana gang kampung-kampung Wisata Jarak-Dolly. Elemen estetis dinding akan mentransformasikan bentuk-bentuk jendela dan pintu rumahrumah di pemukiman yang padat dan saling berhadapan.

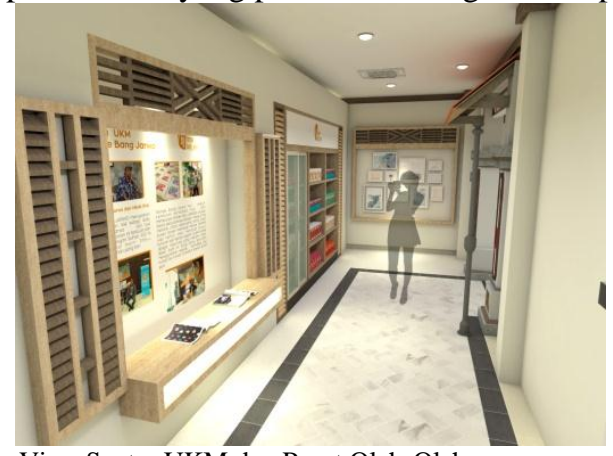

Gambar 10. View Sentra UKM dan Pusat Oleh-Oleh 


\section{3) Konsep Lampu}

Lampu akan menjadi elemen estetis untuk memperkuat karakter dari Sentra UKM serta menjadi sumber pencahayaan utama untuk menerangi infografi dan membuat presentasi dari elemen informatif tersebut lebih terlihat menarik.

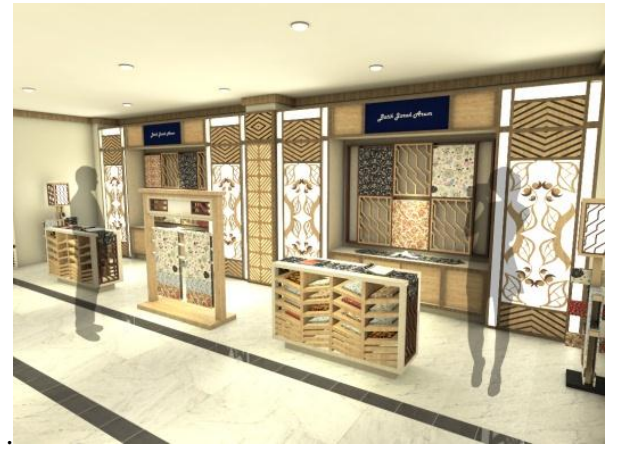

Gambar 11. View Sentra UKM dan Pusat Oleh-Oleh

\section{4) Konsep Elemen Estetis}

Konsep elemen estetis merupakan pengaplikasian dari ketiga nilai pada konsep makro, yaitu nilai edukatif, nilai pembinaan, dan nilai historis. Salah satu penerapan konsep elemen estetis adalah transformasi dari suasana gang kampung wisata Jarak-Dolly, salah satunya transformasi suasana dan replika dari bentuk gapura gang yang menjadi entrance dari masing-masing area display produk di ruang Sentra UKM dan Pusat Oleh-Oleh.

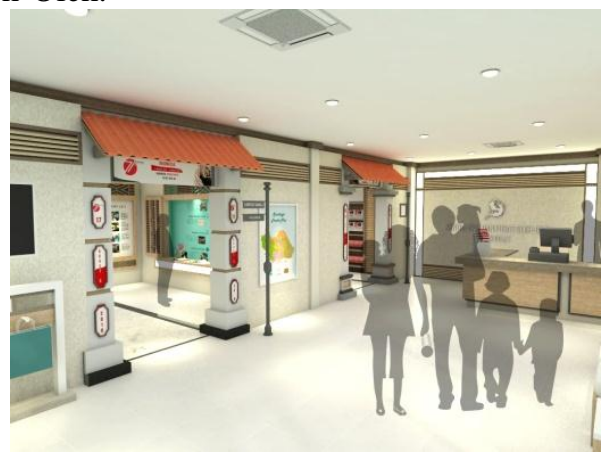

Gambar 12. View Sentra UKM dan Pusat Oleh-Oleh

\section{5) Furniture}

Furniture yang digunakan adalah furniture-furniture untuk mendukung fungsi dari masing-masing ruang, terdapat tambahan furniture tertentu untuk mendukung konsep makro dari Desain Interior Sentra Interior Ex-Wisma Barbara misalnya terdapat infografis pada area lobby dengan fungsi utama area tunggu untuk memberikan informasi mengenai Jarak-Dolly.

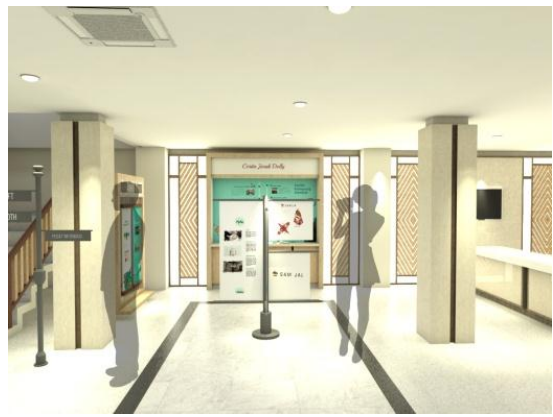

Gambar 13. View Sentra UKM dan Pusat Oleh-Oleh

\section{DESAIN AKHIR}

\section{A. Ruang Sentra UKM dan Pusat Oleh-Oleh}

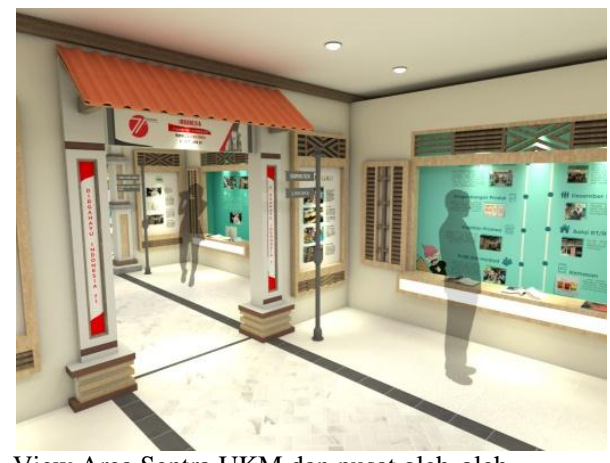

Gambar 13. View Area Sentra UKM dan pusat oleh-oleh

Ruang Sentra UKM dan Pusat Oleh-Oleh adalah ruang display produk UKM Makanan Olahan, yaitu produk dari UKM-UKM binaan gerakan melukis harapan dan terdapat display produk UKM Kota Surabaya. Suasana ruang merupakan transformasi dari suasana gang kampung wisata kawasan Jarak-Dolly.

\section{B. Ruang Lobby}

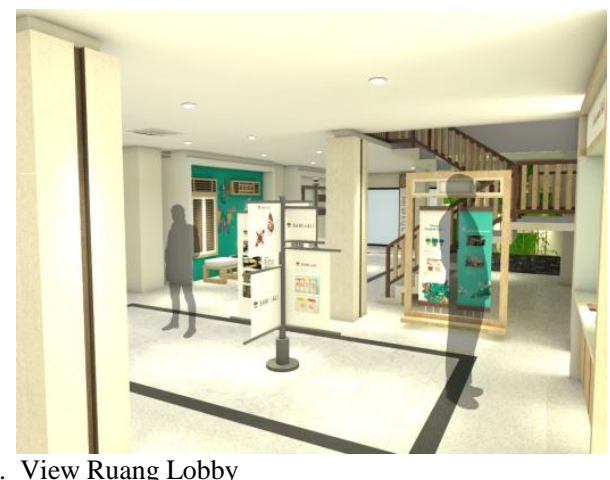

Gambar 14. View Ruang Lobby

Ruang Sentra Lobby berfungsi sebagai area sirkulasi menuju ke masing-masing ruang dan lantai dari Sentra UKM ini, lobby juga memiliki fungsi sebagai ruang pusat informasi dan tunggu bagi pengunjung. Terdapat elemen estetis yang merupakan transformasi dari suasana ruang Sentra UKM dan gang kampung wisata sehingga pengunjung akan merasakan menunggu di masing-masing tempat tersebut.

\section{Ruang Pusat Kerajinan Batik dan Textil}

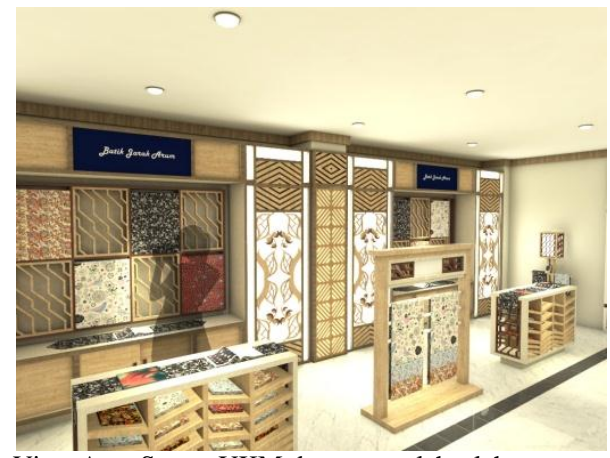

Gambar 15. View Area Sentra UKM dan pusat oleh-oleh 
Ruang Sentra Pusat Kerajinan Batik dan Textil adalah ruang untuk mendisplay produk-produk batik dan textil dari UKM binaan Gerakan Melukis Harapan, Elemen estetis dari ruang ini salah satunya merupakan transformasi bentuk dari motif batik dari UKM Jarak Arum.

\section{KESIMPULAN}

Pelaksanaan studi ini diharapkan akan dapat memberikan manfaat, baik bagi diri penulis, almamater (Institut Teknologi Sepuluh Nopember), pihak Pemerintah Kota Surabaya dan kawasan Jarak-Dolly pada khususnya.

Dengan adanya kegiatan studi ini diharapkan kerjasama antara perguruan tinggi dengan pemerintah kota akan terus terjalin, sehingga proses transfer teknologi dari lingkungan masyarakat ke perguruan tinggi dan sebaliknya akan berjalan dengan baik dan bermanfaat bagi masyarakat sehingga akan tercapai masyarakat yang memiliki kemandirian ekonomi khususnya masyarakat di kawasan ex-lokalisasi Jarak-Dolly.

Demikian jurnal ini dibuat dengan harapan dapat memberikan gambaran singkat dan jelas, serta gagasan penulis tentang Studi Desain Interior Ex-Wisma Barbara sebagai Sentra UKM kawasan Jarak-Dolly. Semoga jurnal ini dapat berkontribusi untuk keilmuan Desain Interior, pengembangan Kota Surabaya dan Jarak-Dolly serta bentuk pengabdian masyarakat yang bisa penulis berikan bagi lingkungan.

\section{DAFTAR PUSTAKA}

[1] Purnomo dan Siregar. April 1982. Membedah Dunia Pelacuran Surabaya, Kasus Kompleks Pelacuran Dolly. Grafiti Pers.

[2] Wardhana, Mahendra. 2016. Spatial Analysis Of User Movement Pattern \& Its Socialization On Public Facilities \& Environment Through The ESVA. Procedia Social And Behavioral Sciences. p. 101-106.

[3] Wardhana, Mahendra. 2015. Spatial Analysis In Human Behavior In The Environment To Predict Its Movement And Confort. ISIC2015. ISICO 2015. 